\title{
O QUE ENSINAM E COMO ENSINAM OS LIVROS DIDÁTICOS DE HISTÓRIA PARA OS ADOLESCENTES? UMA EXPERIÊNCIA DE LEITURA CRÍTICA DO GUIA DE LIVROS DIDÁTICOS DE HISTÓRIA - ANOS FINAIS DO ENSINO FUNDAMENTAL ${ }^{1}$
}

\author{
WHAT AND HOW DO HISTORY SCHOOLBOOKS TEACH TEENAGERS? \\ A CRITICAL READING EXPERIENCE FROM THE HISTORY TEXTBOOK GUIDE - \\ FINAL YEARS OF ELEMENTARY SCHOOL
}

Daniela Casoni Moscato

\begin{abstract}
Resumo: Este texto é um relato de minha experiência de leitora crítica para o "Programa Nacional do Livro e do Material Didático (PNLD) de 2017" e de minha apresentação na mesa redonda do evento "Livro didático de história: conhecimento histórico e didática da história no mundo contemporâneo", em 2017. Desta forma, trago neste artigo a descrição das etapas do trabalho que realizei, a leitura das resenhas e apresentação de minhas apropriações, e possíveis reflexões sobre o GUIA de História 2017. Como uma das três leitoras das resenhas das coleções aprovadas pela equipe avaliativa, realizei este trabalho seguindo os critérios de fichas de análise e de acordo com o meu lugar social: o de professora de História da rede pública de ensino. Escreverei desse mesmo lugar.
\end{abstract}

Palavras-chaves: Ensino de História; PNLD; Guia de Livros Didáticos; Leitora-crítica

\begin{abstract}
This text is an account of my experience as a critical reader for the "National Book and Teaching Material Program (PNLD) of 2017" and my presentation at the roundtable of the event "History textbook: historical and didactic knowledge of history in the contemporary world "in 2017. Thus, I bring in this article the description of the stages of the work that I accomplished, the reading of the reviews and presentation of my appropriations, and possible reflections on the GUIDE for History 2017. As one of the three readers of the reviews of the collections
\end{abstract}

1 - Agradeço às professoras Marlene Rosa Cainelli e Sandra Regina Ferreira de Oliveira pelo convite para participar da mesa redonda do evento Livro didático de história: conhecimento histórico e didática da história no mundo contemporâneo em 2017 e que dá o título a esta publicação. A participação que tive no PNLD 2017 permitiu o registro da minha experiência leitora e, acima de tudo, aprofundar meu conhecimento sobre o trabalhoso processo de avaliação dos livros didáticos brasileiros destinados às escolas públicas.

2 Doutora em História pela UFPR. Professora de História/SEED-PR e integrante do CEIbero Cultura e Educação nos Impérios Ibéricos. 
approved by the evaluation team, I carried out this work following the criteria of analysis cards and according to my social place: that of teacher of History of the public school network. I'll write from the same place.

Key-words: History teaching; PNLD; Guide to Didactic Books; Readercritic.

\section{Introdução}

\section{O convite}

Este artigo começa com um esclarecimento. Ele foi escrito a partir do meu lugar social e de uma função que exerci no PNLD de 2017. Sou professora de História na rede pública de ensino do Paraná há 13 anos. Nesse período, lecionei nos anos finais do Ensino Fundamental, Ensino Médio e Educação para Jovens e Adultos. Em 2016, recebi o convite para participar do PNLD como leitora crítica do Guia de livros didáticos de História dos anos finais do ensino fundamental. Portanto, minhas reflexões estão atreladas à essa posição.

O trabalho que me coube no Guia do PNLD 2017 foi desempenhado por meio de instruções e roteiros para a leitura crítica das resenhas. As considerações advindas das leituras foram expostas durante dois dias, em reuniões com os membros da equipe: "leitoras-críticas", "coordenadora pedagógica", "assessora" e "coordenadora do Guia" - Guia do Livro Didático. Em 2017, dando prosseguimento às atividades do PNLD, participei da mesa redonda $O$ que ensinam e como ensinam os livros didáticos de História para os adolescentes? com a Prof ${ }^{a}$ Dr $^{\mathrm{a}}$ Márcia Elisa Teté Ramos e o Prof. Dr Ronaldo Cardoso Alves.

Após essas duas experiências, retomei o material que me foi enviado, para escrever sobre a atividade de leitora crítica no PNLD. No entanto, precisei entender, mesmo de modo conciso, o Programa. Seguindo essa premissa, a primeira seção do relato traz alguns dados, já muito tratados pela bibliografia dedicada ao tema, mas que me foram caros à compreensão do PNLD. Nos limites deste texto, exponho, na segunda parte, minha 
experiência como leitora: a etapa da qual participei e qual foi o meu trabalho. Ainda ressalto, nessa seção, como é, para mim, significativa a participação de uma representante de professoras e professores da rede pública no processo de avaliação dos livros didáticos.

\section{Uma rápida explanação a respeito dos programas de políticas públicas e estratégias democratizantes de ensino e sobre os Guias de livros didáticos de História.}

Para a escrita deste artigo, busquei algumas informações sobre o PNLD e os GLDs, que são do conhecimento de pesquisadores e pesquisadoras da área de História da Educação e Ensino de História; entretanto, para mim, são um terreno pouco conhecido de novos temas, autoras e autores. Nessa leitura extremamente necessária, percebi as alterações dos programas que contemplaram os livros e materiais didáticos; um pequeno exercício de reformulação da "História e historiografia sobre PNLD" que estendeu a minha compreensão sobre os GLDs. Até então, o Guia era somente um "companheiro" nas escolhas dos livros didáticos de História. Ler, reler e registrar as impressões sobre as coleções selecionadas era (e ainda é) um apoio para as justificativas expostas aos colegas da área. No entanto, a bibliografia especializada apresentou o Guia como um dos documentos de um programa público e educativo de proporções e gastos gigantescos; um material datado e, portanto, repleto de apontamentos singulares. Desta forma, retomar o já-dito de muitos especialistas do Ensino de História é fundamental neste artigo.

Sobre as políticas públicas para livros didáticos, vale lembrar que a relação Estado/livro didático não é recente. Em 1938, instituiu-se a primeira ideia de uma avaliação de livros didáticos brasileiros, que foi nomeada de "Comissão Nacional do Livro". Desde então, as exigências, o aperfeiçoamento do livro didático e a legislação sobre esses materiais pedagógicos alteram-se em programas e comissões singulares. Como exemplo, tem-se as comissões e programas conhecidos como a "Comissão 
Nacional do Livro Didático" (1945), a "Fundação Nacional do Material Escolar" (Fename, 1967), a "Comissão do Livro Técnico e Didático" (Colted, 1966), o "Instituto Nacional do Livro" (INL, 1972) e os "Programas do Livro Didático" (Plid) abrangendo os diferentes níveis de ensino.

Nos anos 1980, a Fundação de Assistência ao Estudante (FAE) absorveu os projetos responsáveis pelos livros didáticos. Foi também nessa década que o Ministério da Educação (MEC) passou a ser o único comprador dos livros produzidos para o Programa. Em agosto de 1985, o Plid recebeu a denominação de "Programa Nacional do Livro Didático" (PNLD). O programa tinha como objetivo atender a todas as alunas e alunos da $1^{\text {a }}$ à $8^{a}$ séries, hoje Ensino Fundamental I e II, das escolas públicas federais, estaduais e municipais (HÖFLING, 2000, pp.162-164). Entre outras atribuições, o Decreto $n$ 91.542/1985 propunha que os professores do antigo ensino de $1^{\circ}$ grau participassem da escolha e da "indicação dos títulos dos livros a serem comprados pelo governo e adoção de livros reutilizáveis" (CAIMI, 2017, p.34).

Nos anos 1990, a distribuição de livros às alunas, alunos e professores das redes de ensino público, tornou-se política de Estado. Percebe-se o crescimento gradativo da universalização e distribuição do livro didático. Foi também nessa década que os materiais enviados pelas editoras de livros didáticos começaram a ser avaliados pedagogicamente pelas Comissões Técnicas específicas compostas por especialistas de diferentes áreas do conhecimento (HÖFLING, 2000, p.168). Do mesmo modo, se projetou ferramentas de escolha e avaliação dos livros didáticos que considerariam tanto a qualidade física do material como o conteúdo metodológico-conceitual proposto pelos autores. Esse planejamento deu-se por diversas etapas e alterações; tem-se dentre elas:

[...] a gradativa inserção de componentes curriculares no processo avaliativo; a contratação de universidades públicas para coordenar a avaliação pedagógica das coleções inscritas mediante edital; a definição de critérios de natureza técnica e pedagógica, resguardando não só as especificidades físicas dos livros, mas sobretudo as formulações metodológicas e conceituais; preocupações crescentes com a superação de erros, anacronismos, simplificações explicativas, esteriótipos; investimentos no combate a preconceitos de 
diversas naturezas e na incorporação de políticas de ações afirmativas [...] (CAIMI, 2017, pp.34-35).

Além das disciplinas de Português e Matemática, o Programa contemplou, em 1996, a de Ciências e, em 1997, as de Geografia e História. Em 1996, foi publicado o primeiro "Guia de Livros Didáticos" de $1^{a}$ a $4^{a}$ séries. (www.fnde.gov.br/acesso em 07/08/2018) e, em 1999, os guias de $5^{\mathrm{a}}$ a $8^{\mathrm{a}}$ séries (GRAMOWSKI; RAMOWSKI; DELIZOICOV, 2017, p. 03). Tal material, destinado aos profissionais da educação pública, tem como objetivo apoiar as escolhas dos livros didáticos nas escolas brasileiras. Sobre os critérios e propostas das avaliações realizadas pelo MEC, de acordo com o site oficial do FNDE, os livros foram e são "avaliados pelo MEC conforme critérios previamente discutidos. Esse procedimento foi aperfeiçoado, sendo aplicado até hoje. Os livros que apresentam erros conceituais, indução a erros, desatualização, preconceito ou discriminação de qualquer tipo são excluídos do Guia do Livro Didático. (BRASIL,2018)

O processo de seleção dos livros didáticos inicia-se a partir da publicação do MEC, no Diário Oficial, dos editais destinados às editoras brasileiras. Feita a averiguação pelo Instituto de Pesquisas Técnicas da Universidade de São Paulo das normas técnicas e físicas exigidas pelos editais, inicia-se avaliação didática, pedagógica e metodológica das obras (GRAMOWSKI; RAMOWSKI; DELIZOICOV, 2017, p. 03) Essa etapa é realizada pelos editais de chamada pública emitidos pela Secretaria de Educação Básica (SEB) do Ministério da Educação. Os documentos convocam as instituições públicas de ensino superior a participarem da coordenação das avaliações pedagógicas de obras inscritas no Programa Nacional do Livro Didático. Os interessados devem apresentar o projeto de avaliação pedagógica e a equipe de avaliação.

Atualmente, o Fundo Nacional de Desenvolvimento da Educação (FNDE) é o órgão responsável pela operacionalização do PNLD, que, após o decreto $\mathrm{n}^{\circ}$ 9.099, de julho de 2017, tem uma nova nomenclatura, "Programa Nacional do Livro e do Material Didático". Nessa proposta, incluíram-se outros produtos pedagógicos, dentre eles: jogos educativos, 
softwares educacionais e materiais referentes a gestão escolar. (BRASIL, 2018).

Já se mencionou que os GLDs são resultados de avaliações das coleções aprovadas nas diferentes áreas de conhecimento. Esses documentos, destinados às professoras e professores, devem apoiar as escolhas dos livros didáticos que serão usados durante um triênio. Geralmente, trazem em suas primeiras páginas as informações de gestões públicas, ou seja, dados dos secretários, presidentes, diretores e coordenadores do MEC, SEB e FNDE e os membros das equipes técnicas operacionais, pedagógicas e avaliativas.

Até o PNLD 2002, os Programas disponibilizavam aos docentes as classificações das coleções RD (Recomendada com Distinção), REC (Recomendada) e RR (Recomendada com Ressalvas). O GLD 2002 era um encarte único, em que constavam as avaliações de coleções aprovadas para todas as áreas de ensino. As considerações das equipes de especialistas eram expostas antes do conjunto de resenhas e eram demarcadas por cores distintas: Língua Portuguesa, em alaranjado; Matemática, em azul; Ciências, em roxo; História, em marrom; e Geografia, em verde. As resenhas continham os seguintes blocos: Por quê?; A Coleção; Análise e Em Sala de Aula. (Brasil, 2001)

A partir do PNLD 2005, observa-se outro formato à apresentação dos resultados avaliativos. Publicou-se um Guia para cada área de ensino e as indicações das coleções foram "substituídas pela classificação Aprovada ou Excluída. A gradação entre as diversas coleções ficou a cargo das resenhas publicadas no Guia do livro didático" (BEZERRA, 2017, p. 77). Nesse Guia, as resenhas apresentavam as seguintes divisões: $A$ coleção; $A$ análise e $E m$ sala de aula. Há, também, que se destacar o aperfeiçoamento dos critérios em relação às abordagens e aos conteúdos, como o notado nas avaliações dos Programas de 1999, 2002 e 2005:

Na área de História é patente a transformação: de um cenário marcado pelo predomínio de obras que veiculavam, de modo explícito ou implícito, todo o tipo de esteriótipos e/ou preconceitos, para um quadro em que predominavam 
cuidados evidentes, por parte de autores e editores, em relação aos critérios de exclusão de uma obra didática. Nos vários editais e nos Guias publicados, tais critérios têm sido exaustivamente repetidos: existência de erros de informação, conceituais ou de desatualizações graves; veiculação de preconceitos de gênero, condição social ou etnia, bem como de quaisquer formas de proselitismo e, por último, verificação de incoerências metodológicas graves entre a proposta explicitada e aquilo que foi efetivamente realizada ao longo da obra. (MIRANDA; DE LUCA, 2004, pp. 127-128).

Com relação aos textos que antecedem as resenhas, destinados às professoras e aos professores, pode-se dizer que apresentam as singularidades das equipes avaliativas e os critérios gerais e específicos, do Edital do PNLD do ano. Os Sumários dos Guias de 2005 a 2014 seguem, mais ou menos, um padrão editorial: carta ou apresentação ao(a) professor(a), os critérios e métodos avaliativos, resenhas das obras aprovadas, fichas de avaliação e referências bibliográficas. Entretanto, no Guia do PNLD de 2008, as coleções aprovadas foram divididas em quatro blocos, de acordo com a organização do conteúdo: "História Temática", "História Integrada", "História Intercalada" e "História Convencional", esta última com apenas uma coleção aprovada. Do mesmo modo, percebe-se abordagens singulares nos textos principais, como o GLD 2014 que trouxe ao leitor o item O PNLD e o Ensino de História, (BRASIL, 2013).

Os estudiosos do PNLD corroboram a ideia de que as mudanças nos diferentes GLDs têm como alvo os docentes da educação básica, principais interessados no documento. Entre as solicitações identificadas nesses anos, estavam os formatos das resenhas sobre as coleções dos livros que, por seguirem o mesmo padrão, não evidenciavam:

[...] as diferenças entre as coleções e os livros. Solicitavam parâmetros claros de distinção entre as obras aprovadas e foi, nesse sentido, que os Guias passaram a publicar gráficos, tabelas comparativas, e, a partir do Guia do PNLD 2008, análises gerais das coleções e dos livros em textos introdutórios e reservando para as resenhas as características mais específicas das publicações. (OLIVEIRA, 2017, p.57). 
Essas adequações podem ser percebidas nos Guias 2008, 2011, 2014. Entretanto, os recursos como tabelas e gráficos são apresentados aos leitores nos textos que esclarecem os métodos avaliativos das equipes ou os debates sobre o Ensino de História. Isso pode ser observado no Guia 2008:

Figura 1- Guia de Livros Didáticos 2008

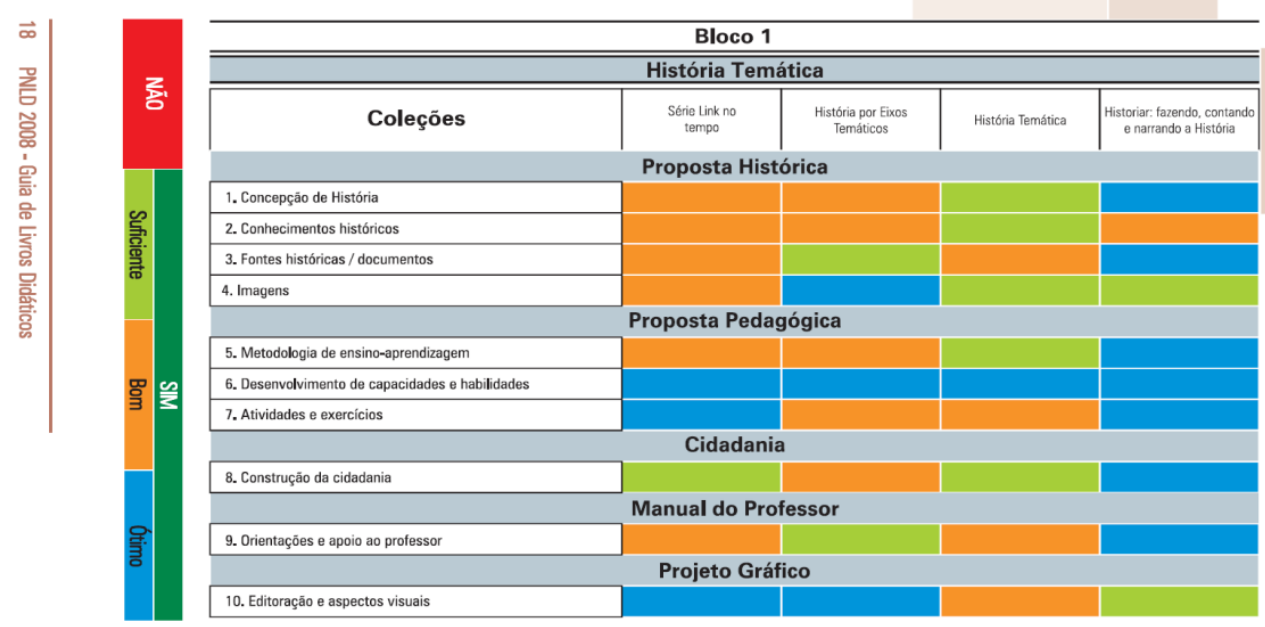

No Guia 2014, ainda não há nas resenhas nenhum recurso visual e elas são, em sua maioria, apresentadas aos leitores com as seguintes abordagens: "Visão Geral da Obra, "Descrição da Coleção" e "Análise da Obra".

Essa concisa explanação constata que os GLDs podem ser considerados como fonte pertinente para uma análise historiográfica amparada nas ferramentas teórico-metodológicas das diferentes dimensões, abordagens e domínios presentes na área. Dentre as possibilidades de investigação já realizadas, tem-se, em sua maioria, a de encontrar nos GLDs elementos que possibilitam pensar as mudanças ocorridas nos materiais didáticos desde o princípio das avaliações, no final dos anos 1990. Esses dados e aspectos podem ser apresentados nos textos que introduzem as resenhas, os quais exibem reflexões como as das preocupações que presidem a avaliação das coleções da área de História (CAIMI, 2017). Do 
mesmo modo, revela articulações e estratégias pedagógicas percebidas pelos resenhistas como os das tendências historiográficas durante algumas edições (MIRANDA; DE LUCA, 2004). O conjunto de Guias já publicados oportuniza, ainda, depreender as práticas avaliativas das equipes contempladas, bem como as rupturas e as permanências que, como na História, se apresentam nas investigações da área e, portanto, nos livros didáticos. $\mathrm{E}$, finalmente, as coleções de livros aprovadas e publicadas nos Guias, e a exposição dos critérios avaliativos de cada edição, permitem avaliar como as exigências didático-pedagógicas atuam na demanda mercadológica:

\begin{abstract}
Dessa forma, convém ressaltar a importância das avaliações feitas pelo MEC no sentido de fornecer um crivo para a escolha a ser feita pelos professores. Trata-se de uma tarefa extremamente complexa, mas que oferece uma visão crítica através das resenhas elaboradas por uma equipe especializada. Se, por um lado, os programas ainda apresentam deficiências estruturais, por outro vêm mostrando ser uma maneira cada vez mais eficiente de pressionar o mercado, no intuito de fornecer obras pertinentes do ponto de vista formal e historiográfico (FERREIRA; FRANCO, 2008, p. 84).
\end{abstract}

\title{
3. A experiência de leitora crítica do Guia de livros didáticos de História 2017
}

Para o relato que proponho, quero esclarecer rapidamente que 0 leitor crítico tem como função contemplar, nos textos, os itens introdutórios e elaborados para cada edição dos GLDs e, sobretudo, ler todas as resenhas elaboradas para cada uma das coleções aprovadas. Devem-se seguir determinadas instruções de leitura e preencher as fichas de análise para cada resenha, terminada esta etapa, os leitores encontram-se com alguns membros da equipe de avaliadores. Nessa ocasião, são expostos os resultados das análises e debatidas possíveis modificações antes da finalização. A função de leitores críticos do material destinado aos docentes é encontrada a partir do Guia de História de 2011. Em 2011 e 2014, houve dois leitores críticos. Na edição de 2017, encontram-se três. 
O Guia 2017 foi liderado pela Universidade Estadual de Londrina (UEL), que teve a candidatura escolhida pelo Ministério da Educação para a área de História, por meio da Chamada Pública SEB/MEC $\mathrm{n}^{\circ} 1 / 2015$. Todos os membros estão elencados em cada uma das funções do processo avaliativo: Comissão técnica, Equipe responsável pela avaliação de recursos, Coordenação Pedagógica, Coordenação Institucional, Coordenação Pedagógica do guia do livro didático, Coordenação adjunta, Avaliadores, Leitura crítica, Grupo focal, Revisão de texto e Apoio técnico-administrativo. Nos textos introdutórios, a Equipe esclarece aos docentes a relevância do Guia na escolha dos livros didáticos. Do mesmo modo, apresenta a disciplina de História nos anos finais do ensino fundamental; elenca e disserta sobre os princípios e critérios avaliativos; apresenta uma reflexão sobre as coleções aprovadas e alguns avanços identificados. A segunda parte do Guia contém as 14 resenhas das coleções e as fichas de avaliação.

Aceito o convite para participar dessa etapa do Programa, foi-me enviado um documento com as instruções e roteiro para a leitura crítica das 14 resenhas do Guia PNLD-História 2017. No texto, a coordenação e assessoria esclareciam as orientações obrigatórias, elaboradas pela Coordenação Geral de Materiais didáticos - COGEAM, que as resenhas deveriam seguir. Entre os elencados, destacavam-se os objetivos do GLD, como auxiliar o professor na escolha e apoiar a formação docente. As autoras, do mesmo modo, ressaltavam que o Guia não deveria conter "nenhuma indução ou sugestão de ranqueamento das obras aprovadas." Do mesmo modo, a confecção das resenhas teria de seguir determinadas instruções, ou seja, o texto deveria conter um total de $12 \mathrm{mil}$ a $14 \mathrm{mil}$ caracteres, com espaços, o que significava de 04 a 06 páginas e, também, deveria conter as seções: Visão Geral, Descrição e Sumário sintético, Análise da obra e Em sala de aula. No item "Análise da Obra", a autora ou autor dissertaria sobre o "Livro do Aluno", "Manual do Professor" e "Manual do Professor Multimídia".

Essas informações sobre a elaboração das resenhas esclareceram a composição do texto e sinalizaram os elementos que o meu olhar de leitora 
deveria buscar. Por mais que fossem elaboradas por diferentes autores e trouxessem características narrativas e particularidades de cada avaliador, as resenhas deveriam seguir as instruções do COGEAM. A recomendação seguinte foi para que se realizasse a consulta obrigatória dos itens As coleções aprovadas e o panorama da área de ensino de história do Brasil hoje. No texto, havia informações fundamentais sobre os 'Sinalizadores' presentes em cada resenha. Foi, então, a primeira vez que as autoras e os autores lançaram mão de um recurso visual para cada coleção aprovada. As autoras das instruções também enviaram dois anexos: o modelo de Ficha de análise, que seria preenchido para cada resenha, e nosso cronograma de trabalho do IV Encontro do PNLD 2017.

Apesar de ter como trabalho a leitura dos textos de apresentação do GLD 2017, eu não tinha a atribuição de colaborar no debate sobre o Ensino de História e Livro didático que aparecem nessas seções. Entretanto, foram salientados aspectos das coleções aprovadas que merecem ser mencionados; dentre eles, penso que o apontamento do perfil 'conteudista' das coleções aprovadas e o desaparecimento das coleções de História Temática são valorosos. As autoras e autores esclarecem como esses dados limitaram e padronizaram as escolhas dos docents, além de dificultarem a construção de propostas pedagógicas interdisciplinares e transdisciplinares, no ambiente escolar:

O principal efeito desse limite estrutural evidenciado no conjunto das obras e potencializado nesse contexto, no qual desaparecem alternativas didáticas organizadas sob outros formatos e agrupamentos de conteúdos, é a dificuldade de se pautar uma reflexão sistêmica em torno da História do tempo presente, lócus central no qual se organiza a vida do estudante e suas possibilidades de reflexão acerca da dinâmica social. Ao desconsiderar esse tempo no qual se organiza a experiência de vida, o Ensino de História corre o risco de seguir ancorando-se no estudo predominantemente voltado ao passado da humanidade. (BRASIL, 2016, pp. 24 e 25)

Ainda, sobre a ausência das coleções por eixos temáticos ou com organização temática, identifica-se que, em 2005, 17\% das coleções de 
História para os anos finais do Ensino Fundamental "tinha organização temática; no ano de 2008 esse percentual chegou a 24\%; em 2011, registra-se uma queda para o patamar de 7\%; em 2014 novamente sobe para 20\% e no Guia do PNLD 2017 não conta nenhuma coleção temática" (CAIMI, 2017, p.45).

Sobre o papel de leitor crítico, este deveria, sobretudo, preencher uma ficha de análise para cada resenha e contemplar as seguintes temáticas e abordagens: o tratamento escolar das fontes históricas, a relação entre texto-base e atividades, o tratamento das questões de temporalidade histórica, a temática afro-brasileira e a temática indígena. Cada discussão, dessas temáticas e abordagens, foi amparada pelos diagramas denominados de 'Sinalizadores' e essencial entendê-los antes de iniciar a leitura crítica. Assim, cada um era apreciado, por meio de quatro dimensões, necessárias à contemplação da temática específica. Os eixos centrais e suas subdivisões foram exibidos através de diagramas de diferentes cores correspondentes a cada tema e abordagem. Esse recurso visual tinha como objetivo "favorecer um olhar de síntese a respeito da coleção e criar uma ferramenta de amparo a leitura (...)" (BRASIL, 2016, p. 27)

Figura 2 - Sinalizadores

Relação entre textos-base e atividades

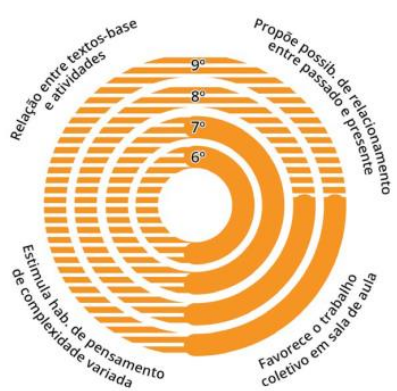

Tratamento da temporalidade histórica

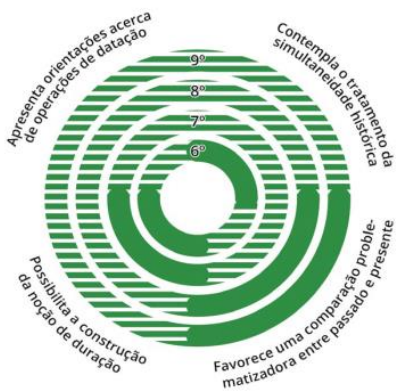

Temática indígena

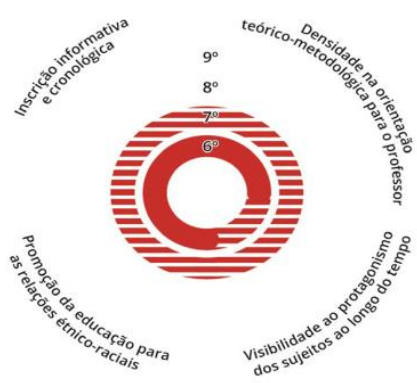

Fonte: Guia de livros didáticos. PNLD 2017: História Ensino Fundamental/anos finais. Brasília: DF, Ministério da Educação, 2016. 
Aqui há que se esclarecer a seguinte questão: qual a intenção de apresentar esses sinalizadores neste meu relato de leitora crítica? Em meu primeiro contato com esses diagramas, deveria compreender a lógica de sua leitura e percebê-los enquanto recursos de todas as resenhas. No intuito de ilustrar o que estou descrevendo, quero destacar os seguintes sinalizadores: o da temática africana e afro-brasileira (leis 10.639/2003 e 11.645/2008) e o do tratamento escolar para as fontes históricas. Os eixos, abaixo, são representados em cores diferentes e exibem suas dimensões particulares, como a Temática africana e afro-brasileira, com a densidade na orientação teórico-metodológica para o professor, visibilidade ao protagonismo dos sujeitos ao longo do tempo, promoção da educação para as relações étnico-raciais e inscrição informativa e cronológica.

Figura 3 - Sinalizadores

Temática africana e afro-brasileira

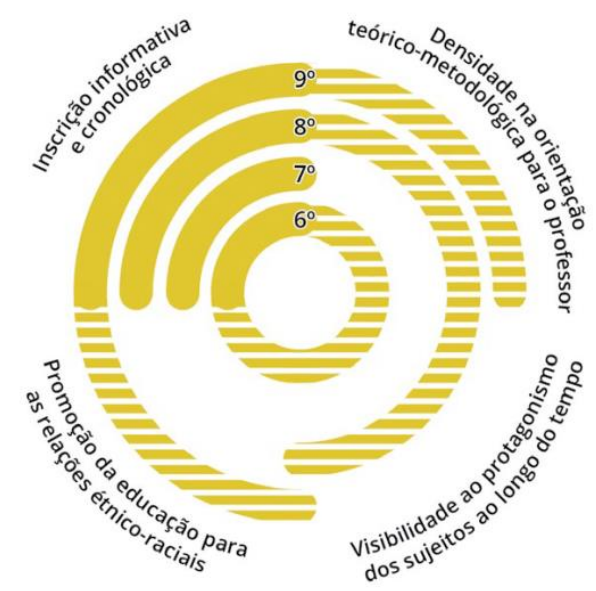

Tratamento escolar das fontes históricas

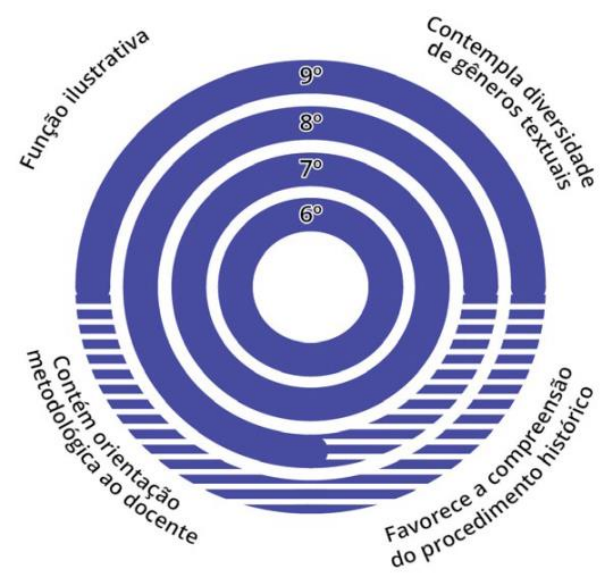

Fonte: Guia de livros didáticos. PNLD 2017: História Ensino Fundamental/anos finais. Brasília: DF, Ministério da Educação, 2016.

Em cada eixo, há quatro círculos que correspondem aos livros de cada um dos anos finais do Ensino Fundamental. A densidade dos preenchimentos dos círculos aponta para o tratamento de cada dimensão. Apenas como ilustração, percebe-se, no eixo azul, o qual sinaliza o 
tratamento escolar das fontes históricas, que a compreensão do procedimento histórico não foi tratada em sua complexidade nos livros dos $8^{\circ}$ e 90 anos.

As 14 resenhas me foram enviadas descaracterizadas e com um código referente a cada coleção aprovada e, tais textos, somente seriam finalizados após o retorno das três leitoras críticas. Tentei, nesse sentido, realizar um trabalho de colaboração, indicando modificações que facilitariam a leitura dos professores e professoras, seguindo as orientações que pediam a avaliação, a validade, a clareza e consistência de cada resenha.

Inicialmente, cumpri as orientações de ordens práticas, tais como adequar os alvos (sinalizadores) ao texto da forma mais assertiva possível. Nessa fase, pontou-se que 04 resenhas não traziam todos os sinalizadores, havia diferenças de nomenclatura no item "Sumário sintético", algumas traziam o item Bibliografia e 05 resenhas não mencionavam o Manual do Professor Multimídia. Na segunda etapa, a leitura deveria ser mais atenta e seguir cada critério da Ficha de Análise:

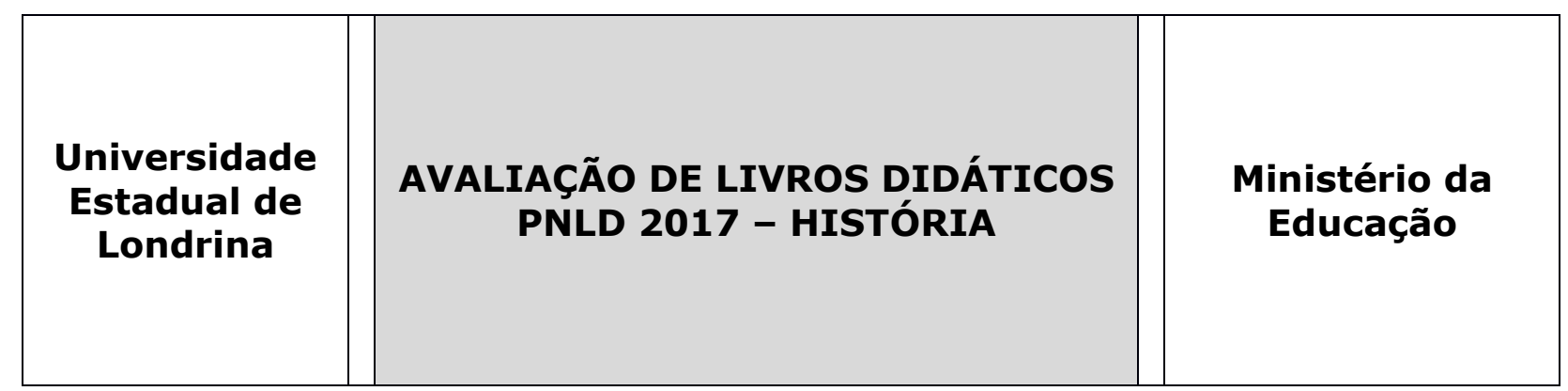

FICHA DE ANÁLISE RESENHA

LEITORA CRÍTICA

COLEÇÃO No:

\begin{tabular}{|l|l|l|l|}
\hline \multicolumn{1}{|c|}{ Critério Sim } & Não & $\begin{array}{c}\text { Em } \\
\text { parte }\end{array}$ \\
\hline $\begin{array}{l}\text { 1. A Visão geral e o Sumário permitem reconhecer a } \\
\text { tipologia, os conteúdos e as principais características da } \\
\text { obra? }\end{array}$ & & & \\
\hline $\begin{array}{l}\text { 2. Há coerência entre as diversas seções da resenha? } \\
\text { (apontar possíveis contradições, repetições). }\end{array}$ & & & \\
\hline
\end{tabular}




\begin{tabular}{|l|l|l|l|}
\hline $\begin{array}{l}\text { 3. Há correção e clareza na escrita (avaliar somente a clareza } \\
\text { - a correção será realizada após a leitura crítica). }\end{array}$ & & & \\
\hline $\begin{array}{l}\text { 4. Os termos, conceitos, expressões e frases estão } \\
\text { adequados para a leitura e compreensão do/a professor/a? } \\
\text { (do ponto de vista historiográfico e do ensino-aprendizagem). }\end{array}$ & & & \\
\hline $\begin{array}{l}\text { 5. Os aspectos negativos da obra são percebidos sem } \\
\text { comprometer os aspectos positivos? (trata-se de coleções } \\
\text { aprovadas no processo) }\end{array}$ & & & \\
\hline $\begin{array}{l}\text { 6. Identifica-se um padrão de escrita no conjunto das } \\
\text { resenhas? }\end{array}$ & & & \\
\hline $\begin{array}{l}\text { 7. As resenhas, no seu conjunto, estão suficientemente } \\
\text { distintas para o professor identificar suas especificidades e } \\
\text { singularidades e cada coleção? }\end{array}$ & & & \\
\hline Indicação dos problemas (para itens com conceito NÃO e EM PARTE): & \\
\hline Observações gerais e sugestões (quando for o caso) & \\
\hline
\end{tabular}

Em relação aos 07 critérios que cada resenha deveria cumprir, apresentei o seguinte resultado:

Quadro 01: Resultado da leitura crítica das resenhas

\begin{tabular}{|l|l|l|l|}
\hline CRITÉRIOS & SIM & NÃO & EM PARTE \\
\hline 01 & 12 resenhas & & 02 resenhas \\
\hline 02 & 04 resenhas & & 10 resenhas \\
\hline 03 & 10 resenhas & & 04 resenhas \\
\hline 04 & 10 resenhas & & 04 resenhas \\
\hline 05 & 12 resenhas & & 02 resenhas \\
\hline 06 & 09 resenhas & 01 resenha & 04 resenhas \\
\hline 07 & 14 resenhas & & \\
\hline
\end{tabular}

Fonte: Guia de livros didáticos. PNLD 2017: História Ensino

Fundamental/anos finais. Brasília: DF, Ministério da Educação, 2016.

Para os itens NÃO e EM PARTE, indiquei os problemas percebidos. Entre eles, a repetição de determinadas informações; a não apresentação das particularidades da coleção; as contradições entre informações textuais e o diagrama; a falta de clareza no objetivo geral das coleções. Expus os pontos de destaque de cada resenha, como o cuidadoso diálogo entre autor 
e leitor, recurso usado pela maior parte de autores ou autoras. Há, também, os destaques às particularidades das coleções; a relação clara entre sinalizadores e seções presentes nas coleções, o enfoque na metodologia e orientação pedagógicas e os esclarecimentos das falhas da coleção sem comprometer o conjunto do projeto.

Essa apreensão dos diagramas, dos textos do GLD 2017 e de cada resenha, foram explanados no IV Encontro PNLD, no mês de abril de 2016. Nos dois dias que seguiram, exibiram-se e debateram-se as diferentes leituras e apontamentos sobre esse material. Tais momentos foram pontuados por reflexões coletivas, amplas e aprofundadas sobre o Guia e, em especial, sobre as resenhas.

\section{Conclusão de uma leitora}

O objetivo deste texto foi apresentar uma experiência de leitura sobre o Guia do Livros Didático de 2017. Entretanto, antes de apresentar as minhas reflexões finais sobre esse material, preciso esclarecer e reafirmar alguns pontos. Desde o último edital público de escolha do material didático destinado aos anos finais do Ensino Fundamental, tive como recurso pedagógico duas coleções diferentes de livros. Durante o ano de 2017, recorri à coleção Projeto Mosaico (VICENTINO; VICENTINO, 2015) e, atualmente, consulto a coleção História nos dias de Hoje (CAMPOS; DOLHINIKOFF; CLARO, 2015). Assim como todos os livros com os quais tive contato durante os meus anos de docente, há críticas a serem feitas a respeito dos diferentes aspectos que perpassam a linguagem, as atividades, os conteúdos e outros. Não ousarei discutir a questão do livro didático, há excelentes estudos sobre o tema. O que quero é reafirmar que o livro didático é necessário. Em muitos casos, é o único livro presente nos lares de alunas e alunos. Em um país de realidades tão singulares, as conclusões precipitadas e pautadas apenas no mundo em que habito não funcionam. E são, de certa maneira, cruéis. 
Nos últimos seis anos de minha carreira docente, saí da minha confortável "bolha institucional" e tive diferentes experiências. Trabalhei em quatro instituições e em três cidades, com diferentes realidades escolares e contextos organizativos singulares. No colégio em que hoje atuo, os únicos recursos que tenho são o giz, o quadro-negro e o livro didático. Estou lotada em uma cidade que tem ligações de redes rodoviárias estaduais e federais, aeroporto e mais de 500 mil habitantes. Isso somente reforça que ainda vivemos em infinitos brasis.

Feito esse necessário informe, retomo a minha participação em uma das etapas do PNLD 2017. Essa foi a de interlocutora com os outros pesquisadores e leitores que participaram do programa. Em termos gerais, o conjunto das resenhas foi assertivo; quando observado o resultado da leitura das 14 resenhas, o item - 2. Há coerência entre as diversas seções da resenha? (apontar possíveis contradições, repetições) - foi o que apresentou mais imprecisões: das 14 resenhas, somente 04 alcançaram o que foi pedido. Ao retomar as minhas anotações e os documentos que me foram enviados, penso que os apontamentos sobre esse assunto diziam respeito, sobretudo, a dois tópicos. O primeiro deles, identificação das secções em cada resenha: Visão geral e nela o subitem Sumário Sintético; Descrição; Análise da obra e Em sala de aula. O segundo, o uso do diagrama e a sua indispensável associação com a secção Análise da obra que dissertava sobre as temáticas e abordagens próprias da área.

Outro tópico que merece ser tratado é o de número 7: As resenhas, no seu conjunto, estão suficientemente distintas para o professor identificar suas especificidades e singularidades e cada coleção?; pois essa era uma das preocupações da equipe avaliativa; era importante que o conjunto tivesse um padrão de escrita. Entretanto, era essencial que prevalecessem as especificidades e singularidades de cada coleção. Esse critério foi notado em todas as resenhas.

Para além de cada item que apresentei, tentei contemplar as seguintes questões: "o que na resenha seria fundamental e esclarecedor 
para professoras e professores que atuam nos últimos anos do EF?" e "o que poderia prejudicar ou confundir a leitura desses docentes?"; todos os apontamentos que realizei foram nesse sentido. Do mesmo modo, o que sinalizei como leitora crítica retirou, de forma alguma, os méritos de autoras e autores das resenhas, mas teve como principal função tornar o PNLD cada vez mais assertivo aos docentes que atuam nos últimos anos do EF. Sempre é importante reforçar que a avaliação seguiu de forma transparente e esclarecedora. É necessário, igualmente, acrescentar que ter uma professora da rede pública - uma representante do público leitor - como umas das leitoras críticas, trouxe uma certa equidade a uma das últimas etapas do PNLD.

Ainda sobre isso, para a escrita deste artigo, retomei os antigos GLDs de História e atentei aos formatos das resenhas e seus conteúdos. Mesmo que essa seja uma leitura superficial, é possível perceber o aperfeiçoamento das resenhas, com o intuito de beneficiar o seu leitor principal. Os textos introdutórios apresentam, aos professores e professoras, questões que acompanham o Ensino de História. Nas resenhas, há indicações que apoiam o trabalho docente e que apontam elementos fundamentais da área. Os diagramas que foram acrescentados no programa de 2017 ilustram o que estou indicando. Esse recurso se tornou mais uma ferramenta de apoio ao momento da escolha do livro didático.

Passados dois anos dessa experiência de leitora, quero apresentar algumas reflexões e concluir, assim, o meu texto. A primeira, já muito discutida na área de Ensino, é que o Guia deveria ser um documento conhecido e estudado pelos docentes; não somente a leitura e a reflexão sobre as resenhas, mas sobre os textos que as antecedem e que apontam significativas questões das abordagens e de temáticas no Ensino de História. Como isso poderia ser realizado? Ao longo das semanas pedagógicas? Em cursos de extensão aos docentes? Nos estudos que realizei e realizo, sob a abordagem da História da leitura, é muito claro que uma comunidade de leitores se constrói por particulares, regras e práticas de leitura. Em outras palavras, há um aprendizado sobre como ler 
determinados formatos do escrito e que formam leitores cada vez mais especializados. Do meu lugar social de professora de ensino fundamental e médio, penso que um espaço físico ou virtual de debate sobre os Guias e seus importantes conteúdos seria uma experiência que vale a pena ser pensada e construída. Lanço esse desafio aos envolvidos.

\section{Referências}

BEZERRA, Holien Gonçalves. O PNLD de história: momentos iniciais. Livros didáticos de história: entre políticas e narrativas. Rio de Janeiro: Editora FGV,20172017, p. 77

BRASIL, Guia de livros didáticos. PNLD 2002: $5^{\mathrm{a}}$ a $8^{\mathrm{a}}$ séries. Brasília: DF, Ministério da Educação, 2001.

. Guia de livros didáticos. PNLD 2005: História. Brasília - $5^{\mathrm{a}}$ a $8^{\mathrm{a}}$ séries DF, Ministério da Educação, 2006.

. Guia de livros didáticos. PNLD 2008: História - Ensino

Fundamental/anos finais. Brasília: DF, Ministério da Educação, 2007.

. Guia de livros didáticos. PNLD 2011: História - Ensino

Fundamental/anos finais. Brasília: DF, Ministério da Educação, 2010.

. Guia de livros didáticos. PNLD 2014: História Ensino

Fundamental/anos finais. Brasília: DF, Ministério da Educação, 2013.

. Guia de livros didáticos. PNLD 2017: História Ensino

Fundamental/anos finais. Brasília: DF, Ministério da Educação, 2016.

BRASIL. Fundo Nacional de Desenvolvimento da Educação. Programas do livro. Brasília: Ministério da Educação. Disponível em www.fnde.gov.br. Acesso em: 07 ago. 2018.

CAMPOS, Flávio de;DOLHINIKOFF, Miriam;CLARO, Regina. História nos dias de hoje - História $6^{\circ}$ ano. São Paulo: Editora Leya,2015.

CAIMI, Flávia Eloisa. O livro didático de história e suas imperfeições:

repercussão do PNLD após 20 anos. In: Rocha, Helenice; REZNIK, Luis;

MAGALHÃES, Marcelo (Orgs.) Livros didáticos de história: entre políticas e narrativas. Rio de Janeiro: Editora FGV,2017,p.33-54.

FERREIRA, Marieta de Moraes; FRANCO, Renato. Desafios do ensino de história. Estudos Históricos, Rio de Janeiro, v.21,n 4,p.79-93,2008.

GRAMOWSKI, Vilmarise Bobato;DELIZOICOV,Nadir Castilho; MAESTRELLI,Sylvia Regina Pedrosa. O PNLD e os Guias dos Livros Didáticos de Ciências (1999-2014): uma análise possível. Revista Ensaio, Belo Horizonte, v.19, p. 01-18, 2017. 
HÖFLING,Eloisa de Mattos. Notas para a discussão quanto à implementação de programas de governo: em foco o Programa Nacional do Livro Didático. Educação\&Sociedade, Campinas, ano XXI, n 70, p. 159-170, abril/2000.

MIRANDA, Sonia Regina; DE LUCA, Tânia Regina. O livro didático de história hoje: um panorama a partir do PNLD. Revista Brasileira de História. São Paulo, v. 24, nº 48, p. 123-144, 2004.

OLIVEIRA, Margarida Maria Dias de. Uma profissional de história em gestão de política pública: como a memória construiu minha experiência no PNLD de 2004 a 2015. Livros didáticos de história: entre políticas e narrativas. Rio de Janeiro: Editora FGV,2017, p. 55-65

VICENTINO, Cláudio; VICENTINo, José Bruno. Projeto Mosaico - História 70 ano. São Paulo: Scipione, 2015. 